\title{
DeepMIP: The Deep-Time Model Intercomparison Project
}

\author{
Daniel J. Lunt', M. Huber², B.L. Otto-Bliesner³, W.-L. Chan'4, D.K. Hutchinson', J.-B. Ladant', P. Morozova7, \\ I. Niezgodzki ${ }^{8,9}$, S. Steinig', Z. Zhang ${ }^{10,11}$ and J. Zhu ${ }^{3}$
}

\begin{abstract}
DeepMIP has brought together the modeling and proxy communities, with an initial focus on the early Eocene climatic optimum, $\sim 50$ million years ago. In addition to evaluating global-scale metrics such as GMST and polar amplification, mechanisms of warmth are also being interrogated.
\end{abstract}

$\mathrm{CO}_{2}$ reconstructions indicate that the closest analogs to potential 22nd-century $\mathrm{CO}_{2}$ concentrations under mid-to-lowmitigation scenarios existed tens of millions of years ago, in "deep-time". The Deep-Time Model Intercomparison Project (DeepMIP; deepmip.org) is dedicated to conceiving, designing, carrying out, analyzing, and disseminating the results of an international effort to improve our understanding of these deeptime climates. Here, deep-time climates are defined as time periods prior to the Pliocene, $\sim 5$ million years ago. At its heart, DeepMIP aims to foster closer links between the paleoclimate modeling and data communities, grow communities of practice, develop and disseminate best practices, and to use this model-data synergy to:

- design, carry out, and analyze appropriate model simulations;

- create, collate, and synthesize proxy datasets; and

- evaluate model simulations, with a dual aim of learning about the past and informing the future.

\section{History of DeepMIP}

Prior to becoming part of PMIP, initial work was kick-started by the publication of several studies which independently modeled the early Eocene ( 50 million years ago), a time period characterized by $\mathrm{CO}_{2}$ concentrations 1200-2500 ppmv, global mean temperatures $\sim 23-30^{\circ} \mathrm{C}$, and the complete absence of ice sheets. The temperature response to the high $\mathrm{CO}_{2}$ concentrations and modified boundary conditions in the models were compared within the framework of an adhoc "ensemble of opportunity" (Lunt et al. 2012). Following on from this, several studies explored other aspects of these simulations, including the hydrology (Carmichael et al. 2016), implications for glaciation (Gasson et al. 2014), or the modification of model parameters (Lunt et al. 2013). However, there was a growing realization that for further progress to be made, a more formal, consistent experimental design and model intercomparison was necessary.

In 2015, in a meeting at NCAR, funded by NERC in the framework of an "International Opportunities Fund" project, the community came together to discuss such a formalization. DeepMIP was founded, and became part of PMIP. DeepMIP now has a membership of 200 scientists, with representation from the modeling as well as the marine and terrestrial proxy communities (deepmip.org/people); there have been a total of six meetings, with the most recent being online (deepmip.org/meetings).

\section{DeepMIP activities and results so far}

The first DeepMIP activity was to formally define a model experimental design for the time periods of interest. These were chosen to be the early Eocene climatic optimum (EECO), the Paleocene-Eocene Thermal Maximum (PETM), and the latest Paleocene. This experimental design was published as part of the PMIP4/CMIP6 Special Issue in GMD (Lunt et al. 2017). Following this, the time periods were more formally defined, guidelines and principles for the synthesis of proxy data and the strengths and weaknesses of various proxies were laid out, and the first version of the DeepMIP proxy database was also published (Hollis et al. 2019).

This proxy database was used to characterize the best estimates of global mean temperature in the three time periods of interest, and their uncertainties (Inglis et al. 2020). A variety of methods was applied to convert the relatively sparse proxy data into global means, ranging from a simple latitudinal-banded average, to Gaussian process regression. These different methods were compared and combined, resulting in estimates for the latest Paleocene, PETM, and

\section{pre-industrial}

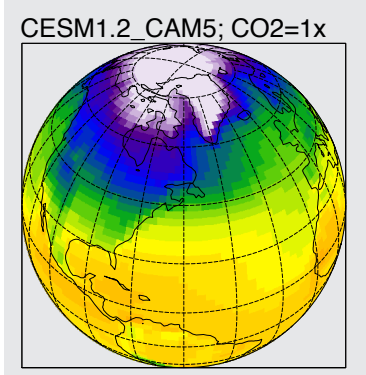

CESM1.2_CAM5; CO2 $=1 \mathrm{x}$

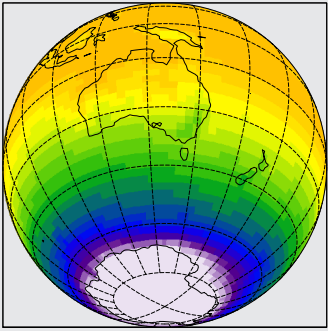

early Eocene

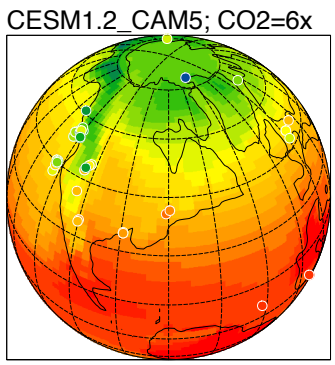

INM-CM4-8; CO2=6x

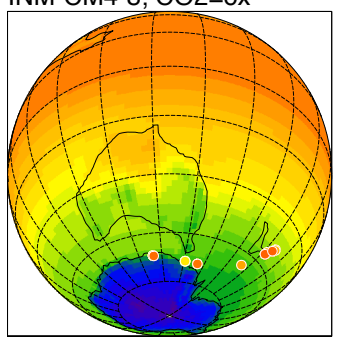

r2413; $\mathrm{CO} 2=3 x$

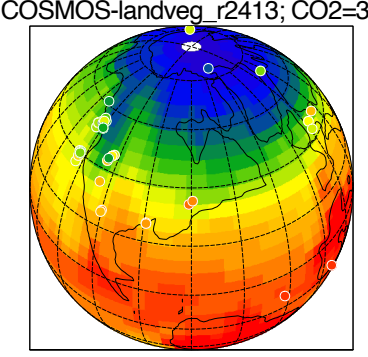

IPSLCM5A2; CO2=3x

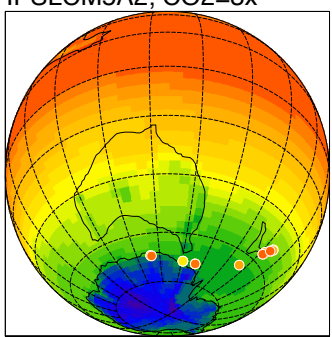

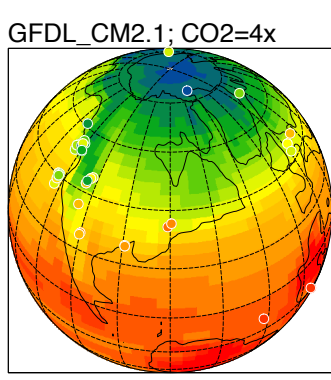

MIROC4m; CO2=3x

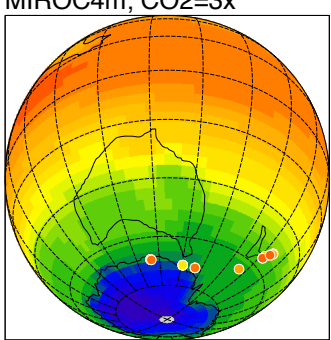

$\begin{array}{llllllll}-16 & -8 & 0 & 8 & 16 & 24 & 32 & 40 \\ \left({ }^{\circ} \mathrm{C}\right)\end{array}$ HadCM3B_M2.1aN; CO2 $=3 \mathrm{x}$

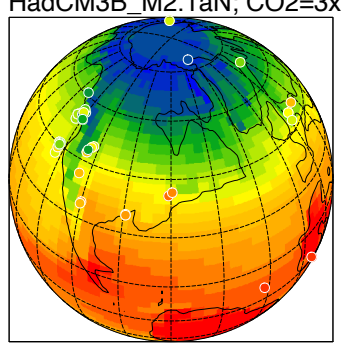

NorESM1_F; CO2=4x

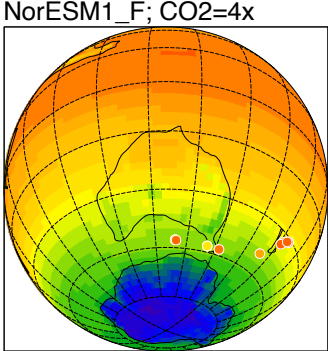

Figure 1: Modeled near-surface annual mean air temperature $\left({ }^{\circ} \mathrm{C}\right)$ from eight models in the DeepMIP-Eocene (early Eocene) model ensemble, and proxy reconstructions from Hollis et al. (2019). The simulations shown here were carried out at a range of $\mathrm{CO}_{2}$ concentrations from 840 ( $3 \times$ pre-industrial) to 1680 ( $6 \times$ pre-industrial) ppmv. Also shown is pre-industrial temperature from the CESM1.2_CAM5 model. The full model results are described in Lunt et al. (2021). The model data can be obtained from the DeepMIP model output database; see here for more info: deepmip.org/data-eocene 
EECO, of $21-29^{\circ} \mathrm{C}, 26-36^{\circ} \mathrm{C}$, and $22-31^{\circ} \mathrm{C}$ respectively ( $90 \%$ confidence interval). This study also used the temperature estimates and the best existing $\mathrm{CO}_{2}$ estimates to provide a quantification of equilibrium climate sensitivity (ECS) based on Eocene data. This resulted in ECS estimates of $1.6-8.0^{\circ} \mathrm{C}$ 1.9-5. $2^{\circ} \mathrm{C}$, and $1.3-5.0^{\circ} \mathrm{C}$ for the same three time periods.

The proxy database was also used to evaluate the DeepMIP model simulations, which were presented, and their large-scale features discussed, in Lunt et al. (2021; see Fig. 1). The work showed that compared with results from previous studies of the Eocene, the DeepMIP simulations show a smaller ensemble spread in the global mean surface temperature response for a given atmospheric $\mathrm{CO}_{2}$ concentration-this may result from the standardised experimental design and topographic/bathymetric boundary conditions.

These simulations also revealed a relatively high Eocene climate sensitivity (ECS) on average (average of $4.5^{\circ} \mathrm{C}$ per $\mathrm{CO}_{2}$ doubling), compared to previous work (average of $3.3^{\circ} \mathrm{C}$ per $\mathrm{CO}_{2}$ doubling). An energy balance analysis of the model ensemble indicated that global mean warming in the Eocene compared with the preindustrial period mostly arises from decreases in emissivity due to the elevated $\mathrm{CO}_{2}$ concentration (and associated water vapor and long-wave cloud feedbacks), whereas the reduction in the Eocene in terms of the meridional temperature gradient is primarily due to emissivity and albedo changes owing to the non- $\mathrm{CO}_{2}$ boundary conditions (i.e. the removal of the Antarctic ice sheet and changes in vegetation).

In contrast with previous work, three of the eight models examined showed results that are consistent with the proxies in terms of the global mean temperature, meridional SST gradient, and $\mathrm{CO}_{2}$. However, at a more regional scale, the models lack skill. In particular, the modeled anomalies are substantially lower than those indicated by the proxies in the southwest Pacific (Fig. 1, lower panels); here, modeled continental surface air temperature anomalies are more consistent with surface air temperature proxies, implying a possible inconsistency between marine and terrestrial temperatures in either the proxies or models in this region.

The results from Lunt et al. (2021) and Inglis et al. (2020) have contributed to the recently published 6th assessment report of the Intergovernmental Panel on Climate Change (IPCC AR6). Individual models that have used the DeepMIP boundary conditions have also contributed exciting results, including the finding that one of the high-ECS CMIP6 models, CESM2.1, produces a climate that is substantially warmer than indicated by the paleoproxies (Zhu et al. 2020; Fig. 2). This result is partly due to the response to the non- $\mathrm{CO}_{2}$ forcings, which suggests that more attention is due on that subject. In addition, one of the low-ECS CMIP6 models, INMCM4-8, produces results at the low end of the proxy temperature estimates (Fig. 2). This indicates that the early Eocene may be a potentially useful tuning target for Earth system model (ESM) development, in particular if tighter constraints can be placed on the $\mathrm{CO}_{2}$ concentration.

\section{Ongoing and future DeepMIP activities}

It is currently a very busy time for DeepMIP scientists, as several papers exploring the model ensemble and proxy data are currently in various stages of preparation. This includes studies focusing on ocean circulation (Zhang et al. submitted), Arctic sea ice (Niezgodzki et al. submitted), and the African monsoon (Williams et al. in prep), and other papers listed here: deepmip.org/ publications-eocene; of these, several studies are proposing to explore the role of paleogeography and ocean gateways on regional climate. It is anticipated that many of these papers will be published in a Special Issue of Paleoceanography and Paleoclimatology, "DeepMIP in the Hothouse Earth: late Paleocene - early Eocene Climates and their lessons for the future", which is being organized by Margot Cramwinckel, Michael Henehan, and Jean-Baptiste Ladant. This work will be aided greatly by the existence of the DeepMIP model outputs database, which contains the model outputs from all eight Eocene models; see here for access: deepmip.org/data-eocene

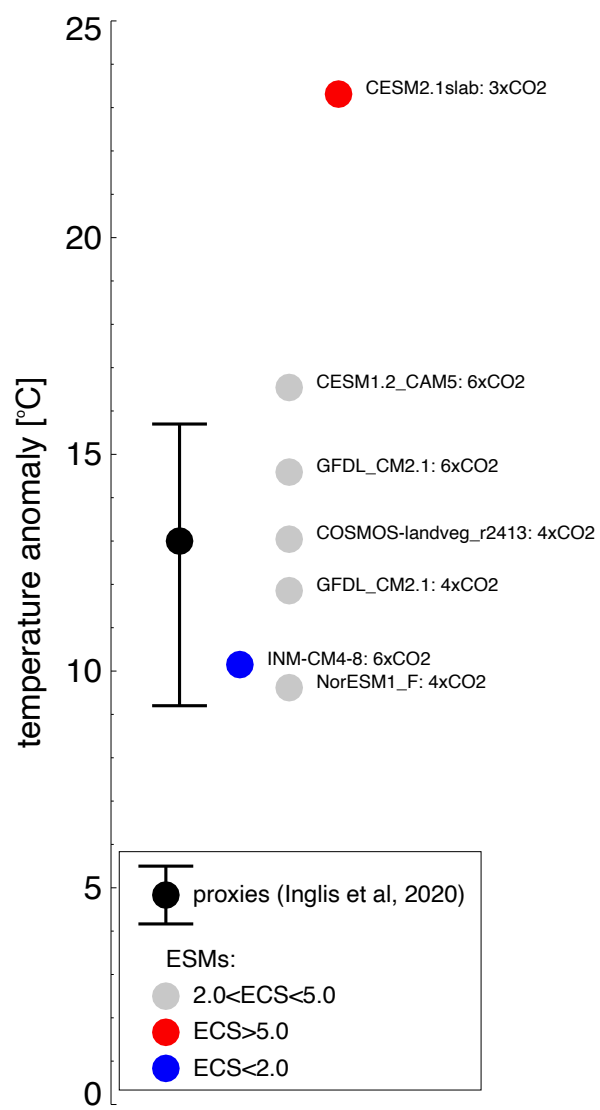

Figure 2: Modeled global-mean near-surface annual mean air temperature $\left({ }^{\circ} \mathrm{C}\right)$ from those model simulations in the DeepMIP-Eocene (early Eocene) model ensemble that carried out simulations at $4 \mathrm{x}$ or $6 \mathrm{x}$ pre-industrial (consistent with proxy $\mathrm{CO}_{2}$ estimates of Anagnostou et al. 2020), plus the $3 x^{2}$ pre-industrial simulation using CESM2.1 (Zhu et al. 2020). Also shown is the proxy-based estimate of global mean temperature from Inglis et al. (2020).
It may be that DeepMIP will explore more time periods over the next few years. Based on experience, we expect that new time periods are best explored initially with ad-hoc ensembles of opportunity. In this regard, there has already been progress on the Eocene-Oligocene Transition (EOT; Hutchinson et al. 2021) and the Miocene (Burls et al. 2021). As such, we have already created three sub-groups within DeepMIP; DeepMIP-Eocene, DeepMIP-EOT, and DeepMIP-Miocene.

In any case, whatever happens, we will always expect DeepMIP to have a focus on integration of models and proxies, and work to bringing the modeling and data communities ever closer.

\section{AFFILIATIONS}

'School of Geographical Sciences, University of Bristol, UK

${ }^{2}$ Department of Earth, Atmospheric, and Planetary Sciences, Purdue University, West Lafayette, IN, USA ${ }^{3}$ Climate and Global Dynamics Laboratory, National Center for Atmospheric Research, Boulder, CO, USA ${ }^{4}$ Atmosphere and Ocean Research Institute, The University of Tokyo, Japan

${ }^{5} \mathrm{Climate}$ Change Research Centre, UNSW, Sydney, Australia

¿Laboratoire des Sciences du Climat et de I'Environnement, LSCE/IPSL, UMR CEA-CNRS-UVSO, Université Paris-Saclay, Gif sur Yvette, France Institute of Geography, Russian Academy of Sciences, Moscow, Russia

${ }^{8}$ Alfred Wegener Institute, Helmholtz Centre for Polar and Marine Research, Bremerhaven, Germany IING PAN - Institute of Geological Sciences, Polish Academy of Sciences, Research Center in Kraków, Biogeosystem Modelling Group, Poland

${ }^{10}$ NORCE Norwegian Research Centre, Bjerknes Centre for Climate Research, Bergen, Norway "Department of Atmospheric Science, School of Environmental Studies, China University of Geosciences, Wuhan, China

\section{CONTACT}

Daniel Lunt: D.J.Lunt@bristol.ac.uk

\section{REFERENCES}

Anagnostou E et al. (2020) Nat Commun 11: 4436 Burls NJ et al. (2021) Paleoceanogr Paleoclimatol 36: e2020PA004054

Carmichael MJ et al. (2016) Clim Past 12: 455-481

Gasson E et al. (2014) Clim Past 10: 451-466

Hollis CJ et al. (2019) Geosci Model Dev 12: 3149-3206

Hutchinson DK et al. (2021) Clim Past 17: 269-315

Inglis GN et al. (2020) Clim Past 16: 1953-1968

Lunt DJ et al. (2012) Clim Past 8: 1717-1736

Lunt DJ et al. (2013) Phil Trans R Soc A 371: 20130146

Lunt DJ et al. (2017) Geosci Model Dev 10: 889-901

Lunt DJ et al. (2021) Clim Past 17: 203-227

Niezgodzki l et al. Simulation of Arctic sea ice within the DeepMIP Eocene ensemble: thresholds, seasonality and factors controlling sea ice development, submitted to Global and Planetary Change.

Williams $C$ et al. The Eocene African monsoon - insight from DeepMIP models and proxy data, in prep.

Zhang Z et al. Early Eocene ocean meridional overturning circulation: the roles of atmospheric forcing and strait geometry, submitted to Paleoceanography and Paleoclimatology.

Zhu J et al. (2020) Nat Clim Chang 10: 378-379 